\title{
Changing Content of the Nursery Grower's Sales Agreement
}

\author{
Roger A. Hinson ${ }^{1}$ and \\ Roberto Navajas
}

ADDITIONAL INDEX WORDS. sales agreement, competition, test of proportions, mass merchandisers, garden centers

\begin{abstract}
Summary. Terms of sale can affect nursery growers' costs. Terms typically have included price, quantity, and quality, but others may be added when growers sell to large customers. Because the industry is very competitive, growers are hesitant to turn down a sale simply because they are asked to pay another cost or provide another service. For this study, a list of items that might be in the terms of sale was developed. Growers were surveyed to determine which of these items were included in the agreement in 1996 and 2001. McNemar's test was used to determine whether proportions of items being added to the agreement were significantly different from items being removed when considering the mass merchandiser and the garden center market channels. Five of the items had significantly more additions to the terms of sale for mass merchandisers, contrasted to four for the garden center channel. Two of these items, apply barcode stickers and continuous inventory replenishment, were significant for both channels. The other significant items for the mass merchandiser channel were provide custom containers, provide returnable shipping equipment, and take back unsold merchandise. These are items can that enhance competitive position and provide cost savings. For garden centers, the other two items with significantly different proportions were attach product information tags, which is a service demanded by consumers, and provide minimum volume, which can reduce the number of suppliers needed in this channel.
\end{abstract}

Department of Agricultural Economics and Agribusiness, LSU AgCenter, 101 Ag Admin Bldg, Baton Rouge, La. 70803.

This document has been approved for publication by the Louisiana State University Agricultural Center as manuscript number 03-12-1398.

${ }^{1}$ Author to whom questions, comments, and requests should be sent; e-mail rhinson@agctr.lsu.edu. 
The nursery industry has experienced significant change over the last 15 years, partly fueled by changes in retailer strategies and practices. The driving forces of change lie in three related areas. First, some individual firms, both at retail and at other levels in the supply chain, are becoming more important as measured by total sales and market share. These firms are large compared to their competitors, and size can influence growers' decisions and other choices within the industry. Second, supply chains are increasingly integrated. Businesses perceive that efficiencies can be gained through scale of operation and better coordination of firms in the supply stream. Third, the capacity of electronic hardware and the capability of software to optimize product movement based on up-to-date information are enabling businesses to better match product supply with demand, and to perform other activities more efficiently.

There are alternative ways to coordinate the transfer of output from producer to consumer. The perfect competition model envisions many independent firms conducting arm's length transactions, in the context of a market where competition forces all firms to produce efficiently. It also is assumed that firms are small and cannot influence the market - that there are no powerful business entities. In the current business environment, however, large firms dominate most industries and influence business practices. Most supply systems are vertically coordinated, through ownership or other arrangement, by a retailer, manufacturer or processor.

One of the factors encouraging the development of vertical coordination as a structural feature of industry, particularly for large firms, is transactions or procurement costs (Tucker and Wilder, 1977). Using fewer but larger suppliers is a way to reduce these costs. But coordinated systems may have other advantages. Supply chains are perceived to contain time and costs that may be reduced. These include avoiding over- or under-production, locating inventories at optimal points, reducing paperwork, and reducing repetitive data entry through electronic transfer of documents.

In agriculture, the pork and poultry industries are examples of consolidation and integration. A relatively few input supplier, processor, and wholesaler firms have captured significant portions of regional and national markets. A similar organization is developing in the fruits and vegetables industry. "Consolidation at the buying end (italics added) of the food marketing system has driven consolidation at the production level" (Carman et al., 1997), and "Increasingly, (in the fruit and vegetable industry) buyers are contracting with growershippers for high volume perishable items to stabilize prices, qualities and volumes” (Carman et al., 1997). “... in key production regions like California and Florida, a few large growers are forward-integrated into the marketing of their own production and the production of other growers ... but shipper structure for many crops is still quite fragmented relative to structure at the buying end of the marketing system" (Cook, 2001).

While the ornamental plant industry has integrated and consolidated less quickly than pork and poultry, mass merchandisers (MMs) have made substantial market share gains. The percentage of households making purchases of lawn and garden products from MMs grew from $32 \%$ of purchasers to $45 \%$ between 1996 and 2001 , and for home centers the values increased from $36 \%$ to $49 \%$ (National Gardening Association, 2002). One of the changes occurring is that large retailers demand use of an electronic format for order placement, inventory management, and reconciliation and payment. Shipments of products are based on real-time sales information rather than forecasts from historical data. Growers unwilling to adopt these innovations may be shut out of the faster growth segment of the market; so, growers increasingly are undertaking activities such as managing the product flow to the market.

Among the many impacts on producers of consolidation and integration may be additional requirements in the terms of sale. Exchange agreements have specified price, quantity, and quality. As they gain influence in the market, retailers also may request or require other services. For example, the grower might be asked to arrange or provide transportation to the retail outlet, to use returnable shipping equipment, to make deliveries at a specific time, or to package/tag products according to the retailer's specification. The situation is similar to the produce industry, where retailers have imposed a set of performance guidelines on their suppliers (Perosio et al., 2001).

In the nursery industry, the business relationship is less formal. Verbal agreements are common. Among the reasons are perishability, absence of well defined grades and standards, and the absence of openly traded markets. The verbal agreement has disadvantages, but in some cases may mitigate risk on both sides of the exchange. Growers' production risk is based on uncontrollable natural processes and on management, and output can vary significantly based on these factors. Buyers understand that failure to deliver can be beyond the grower's control. On the demand side, buyers place orders, but if demand changes and more (or less) product is needed, the agreed-upon quantity may be adjusted. In these cases, it is unusual for either side to demand delivery. This flexible agreement is an additional risk for growers, but most feel it is necessary to work with customers to maintain access to the consumer. Growers know that if they are not willing to work with the customer, others will.

From among the issues discussed, the objective of this study was to identify changes in the terms of the sales agreement. Growers provided information about the expectations of MMs (national chains with full retail categories including lawn and garden) and garden centers (small chains or individual stores that specialize in lawn and garden) by reporting those items that were included in the agreement in 1996 and in 2001.

\section{Materials and methods}

Producer level data were collected from nursery growers through a mail survey (Navajas, 2003). The target population was contained in the Louisiana Department of Agriculture and Forestry's list of licensed nursery growers. From this list, growers with at least 1 acre $(0.4$ ha $)$ of field production, 0.5 acres ( 0.20 ha) of container beds, or 0.04 acres ( 0.016 ha) of greenhouse space, were retained. The total design method (Dillman, 1999) was part of the effort to achieve an acceptable response rate. Respondents with less than $\$ 5,000$ in sales, or who were primarily retailers, were excluded, reducing the target population to 352 . Additional telephone contacts to encourage participation were made. In total, 63 re- 
sponses were received, and of these 38 $(\approx 11 \%)$ were sufficiently complete for use. While this response rate is lower than desired, results should be representative of Louisiana production. All license holders who met the production criteria were invited to respond, and a review of descriptive statistics suggested a reasonable match with characteristics of the state's growers. In addition, results represent a significant portion of the state's production, because 6 of the state's 10 largest growers were among the respondents.

No literature was found that indicated the different dimensions, or terms of sale, included in sales contracts within the nursery industry. Terms of sale chosen for evaluation, then, were based on input from selected nursery growers, experts in the field of environmental horticulture, and information in related literature (Perosio et al., 2001). Nine items were included. They were that product information tags be applied, barcode stickers be applied, special containers be used, transportation to retailer be arranged by the seller, returnable shipping equipment be supplied by the grower, on-time delivery be assured by the grower, unsold merchandise be taken back, minimum volume be supplied by the grower, and continuous inventory replenishment be used. Pretesting of the survey instrument by five growers resulted in some reduction in length and improved organization.

Respondents indicated whether each item was a requirement they had to meet in 1996, and responded again for 2001. The measure of interest was whether the item's status changed between years. McNemar's test allows comparison between sta- tistically dependent samples (Agresti, 1996), which is the case here since each grower responded for both years. The test evaluates the change in proportions. Visualize the data as $2 \times 2$ tables in which the rows show the number of times an item was or not included in 1996, and similarly, the columns contain that information for 2001 . Using " $n$ " to represent the response count, the main diagonal $\left(\mathrm{n}_{11}\right)$ counts growers who indicated an item was not a condition of sale in either 1996 or 2001 , and $\mathrm{n}_{22}$ indicates that the item was a condition of sale in both years. Off the main diagonal, $\mathrm{n}_{12}$ indicates that the item was not a condition of sale in 1996 but was in 2001, or a requirement added. Conversely, $\mathrm{n}_{21}$ indicates when an item was a condition of sale in 1996 but was not in 2001, or a requirement removed. The proportions of interest here are the requirements added and removed, or $\mathrm{n}_{12}$ and $\mathrm{n}_{21}$, respectively. The standardized normal test statistic $(Z)$ is

$\mathrm{Z}=\mathrm{n}_{12}-\mathrm{n}_{21} /\left(\mathrm{n}_{12}+\mathrm{n}_{21}\right)^{1 / 2} \quad$ [Eq. 1] where the terms are defined above. The square of this statistic has a chisquared distribution with one degree of freedom, and tests whether the proportion added $\left(\mathrm{n}_{12}\right)$ differed from the proportion removed $\left(\mathrm{n}_{21}\right)$.

The difference of sample marginal proportions can be used to calculate the sample variance and a confidence interval for the estimator. This is estimated (Agresti, 1996) by

$\mathrm{p}_{1+}\left(1-\mathrm{p}_{1+}\right)+\mathrm{p}_{+1}\left(1-\mathrm{p}_{+1}\right)-2\left(\mathrm{p}_{11} \mathrm{p}_{22}\right.$ $\left.-\mathrm{p}_{12} \mathrm{p}_{21}\right) / \mathrm{n}$ [Eq. 2] where $\mathrm{p}_{1+}$ is the number of respondents who indicated that in 1996 a given item was not included (the row total in the $2 \times 2$ table), and $\mathrm{p}_{+1}$ is the number who indicated that in 2001 the item was not included (the column total). The square root of the estimated variance provides the standard error used in the confidence interval.

The two dominant retail channels, MMs and garden centers, were chosen for comparison. The MM channel includes both general merchandise and home improvement retailers, and is the leading retail channel in sales. Within MMs, supply chain management (SCM) practices, already used in nonperishable categories, are used in the lawn and garden category. SCM's combination of management approach and computer hardware and software applications is a driving force of change in the industry. Suppliers may be required to communicate via Internet connection, where real-time, store-by-store, sales information can enhance their planning efforts (The Economist, 2001). For the retailer, SCM reduces selected management and labor requirements and enables better management of inventory and store space. For many growers, SCM is a new way of doing business that requires time and capital investment.

From a supplier's point of view, independent garden centers differ from mass merchandisers. The group includes small chains and individual stores. Growers and garden centers probably are more similar in size and in other measures. Market areas are more diverse. Average sales per store are likely to be lower. Garden centers may have been slower to integrate electronic technology, so growers would feel less pressure to adopt computer assistance in their operations. Overall, a more balanced relationship between growers and their garden center customers is expected.

Table 1. Number of growers reporting that specific items were removed, unchanged, or added to the sales agreement, by market channel between 1996 and 2001 from a survey conducted in Louisiana in 2002.

\begin{tabular}{|c|c|c|c|c|c|c|}
\hline \multirow[b]{3}{*}{ Item } & \multicolumn{6}{|c|}{ Number of nurserymen reporting by market channel } \\
\hline & \multicolumn{3}{|c|}{ Mass merchandiser channel } & \multicolumn{3}{|c|}{ Garden center channel } \\
\hline & Removed $^{\mathrm{z}}$ & Unchanged $^{x}$ & Added $^{y}$ & Removed $^{\mathrm{z}}$ & Unchanged $^{x}$ & Added $^{y}$ \\
\hline Barcode sticker & 1 & 27 & 10 & 0 & 33 & 5 \\
\hline Custom container & 2 & 25 & 11 & 1 & 37 & 0 \\
\hline Transportation to retailer & 1 & 33 & 4 & 1 & 34 & 3 \\
\hline Take back unsold merchandise & 2 & 28 & 8 & 0 & 38 & 0 \\
\hline Minimum volume & 1 & 36 & 1 & 0 & 34 & 4 \\
\hline Continuous inventory replenishment & 2 & 29 & 7 & 0 & 34 & 4 \\
\hline
\end{tabular}

${ }^{2}$ Removed - the grower said the item was a condition of sale in 1996, but was not in 2001.

${ }^{x}$ Unchanged - the item was either not in the agreement in 1996 and 2001, or was in the agreement in both years.

yAdded-grower said this item was not a condition of sale in 1996, but was in 2001. 
Frequencies of survey outcomes and changes in proportions are reported in Table 1 . As an example, if a nursery did not report that apply barcode stickers was an item in its typical agreement in either 1996 or 2001 , that appears in the "no change" column, and similarly for the case where the barcode sticker was required in both years. The "removed" column for both market channels contains cases where the barcode sticker was a term of sale in 1996, but was not something that had to be done in 2001. The "added" column reports cases where the grower did not have to apply barcode stickers in 1996, but in 2001 the grower did have to attach these stickers.

Retailers were expected to add to the conditions of sale, so the added column should be larger than the removed column. Also, the items that are more important to retailers in each market channel would have larger values in the added column. For both kinds of retailers, results indicate a net addition of most items. The items custom container, barcode sticker, and take back unsold merchandise were more important for the MM channel, while product information tag was highest for garden centers. On-time delivery was infrequently added by MMs. Custom containers, take back unsold merchandise and supply returnable shipping equipment were infrequently added in the garden center channel.

\section{Results}

McNemar's test was used to evaluate the hypothesis that there were no changes in the differences in proportions between the removed and the added columns. These are discussed by item and by market channel in Table 2.

ATTACH PRODUCT INFORMATIONTAGS. For MMs, there was insufficient evidence to reject the null hypothesis for this item at the 0.05 level of significance $(P>0.257)$. This means that for growers' sales to MMs, the requirement to attach product information tags was not more frequently added to the sales agreement than it was removed over the period 1996 to 2001 . Conversely, the null hypothesis was rejected for the garden center model $(P>0.011)$. Attach product information tag was more frequently added as a condition of sale between growers and garden centers than it was removed over the period. The $95 \%$ confidence interval (expected to contain the value of the parameter) was used to interpret the relationship further, as another mea-

Table 2. Results of McNemar's test ${ }^{\mathrm{z}}$ of difference in proportions between items added to and items removed from the sales agreement between 1996 and 2001, by market channel and by item, from a survey conducted in Louisiana in 2002.

\begin{tabular}{|c|c|c|}
\hline \multirow[b]{2}{*}{ Item } & \multicolumn{2}{|c|}{ Market channel } \\
\hline & Mass merchandisers & Garden centers \\
\hline \multicolumn{3}{|l|}{ Attach product information tag } \\
\hline Statistic $(S)(P>S)$ & $1.2857(0.2568)$ & $6.4(0.0114)^{*}$ \\
\hline Difference in sample proportions (se) & $0.08(0.06840)$ & $0.21(0.0759)$ \\
\hline $95 \%$ confidence interval (lower/upper) & $-0.0541 / 0.2141$ & $0.0612 / 0.3588$ \\
\hline \multicolumn{3}{|l|}{ Attach barcode sticker } \\
\hline Statistic $(S)(P>S)$ & $7.3636(0.0067)^{*}$ & $5(0.0253)^{*}$ \\
\hline Difference in sample proportions (se) & $0.24(0.07837)$ & $0.13(0.05455)$ \\
\hline $95 \%$ confidence interval (lower/upper) & $0.0864 / 0.3936$ & $0.0231 / 0.2369$ \\
\hline \multicolumn{3}{|l|}{ Provide custom container } \\
\hline Statistic $(\mathrm{S})(\mathrm{P}>\mathrm{S})$ & $6.2308(0.0126)^{*}$ & $1(0.3173)$ \\
\hline Difference in sample proportions (se) & $0.21(0.08824)$ & $-0.03(0.13501)$ \\
\hline $95 \%$ confidence interval (lower/upper) & $0.0371 / 0.3829$ & $-0.2946 / 0.2346$ \\
\hline \multicolumn{3}{|l|}{ Transportation to retailer } \\
\hline Statistic $(S)(P>S)$ & $1.8(0.1797)$ & $1(0.3173)$ \\
\hline Difference in sample proportions (se) & $0.08(0.05745)$ & $0.05(0.05184)$ \\
\hline $95 \%$ confidence interval (lower/upper) & $-0.0326 / 0.1926$ & $-0.0516 / 0.1516$ \\
\hline \multicolumn{3}{|l|}{ Returnable shipping equipment } \\
\hline Statistic $(S)(P>S)$ & $5(0.0253)^{\star}$ & $0(1)$ \\
\hline Difference in sample proportions (se) & $0.13(0.05361)$ & $0(0.03976)$ \\
\hline $95 \%$ confidence interval (lower/upper) & $0.0249 / 0.2351$ & $-0.0779 / 0.0779$ \\
\hline \multicolumn{3}{|l|}{ On-time delivery } \\
\hline Statistic $(\mathrm{S})(\mathrm{P}>\mathrm{S})$ & $1(0.3173)$ & $1.8(0.1797)$ \\
\hline Difference in sample proportions (se) & $0.02(0.02640)$ & $0.08(0.05759)$ \\
\hline $95 \%$ confidence interval (lower/upper) & $-0.0317 / 0.0717$ & $-0.0329 / 0.1929$ \\
\hline \multicolumn{3}{|l|}{ Take back unsold product } \\
\hline Statistic $(S)(P>S)$ & $3.6(0.0578)^{* *}$ & $\mathrm{~N} / \mathrm{A}$ \\
\hline Difference in sample proportions (se) & $0.16(0.07967)$ & $0(0.14958)$ \\
\hline $95 \%$ confidence interval (lower/upper) & $0.0038 / 0.3162$ & $-0.2932 / 0.2932$ \\
\hline \multicolumn{3}{|l|}{ Minimum volume } \\
\hline Statistic $(S)(P>S)$ & $0(1)$ & $4(0.0455)^{*}$ \\
\hline Difference in sample proportions (se) & $0(0.03737)$ & $0.11(0.04949)$ \\
\hline $95 \%$ confidence interval (lower/upper) & $-0.0732 / 0.0732$ & $0.0130 / 0.2070$ \\
\hline \multicolumn{3}{|l|}{ Continuous inventory replenishment } \\
\hline Statistic $(\mathrm{S})(\mathrm{P}>\mathrm{S})$ & $2.7778(0.0956)^{\star *}$ & $4(0.0455)^{*}$ \\
\hline Difference in sample proportions (se) & $0.13(0.07584)$ & $0.1(0.05068)$ \\
\hline $95 \%$ confidence interval (lower/upper) & $-0.0186 / 0.2786$ & $0.0007 / 0.1993$ \\
\hline
\end{tabular}

${ }^{\mathrm{z} A g r e s t i,} 1996$.

*,**Significant at the 0.05 or 0.10 level, respectively. 
sure of how accurately the parameter was estimated. The population value of the difference in the removed proportion and the added proportion was expected to be within the range from 0.061 to 0.358 .

Attach barcode stickers. For the MM channel, the null hypothesis for attach barcode sticker was rejected $(P>0.007)$. A higher proportion of sales agreements added this item to the terms of sale over the time period. For the garden center channel, the null hypothesis also was rejected $(P>0.025)$, so we can say with a high degree of certainty that the added proportion was higher than the proportion removed over the period.

USE CUSTOM CONTAINERS. In the MM channel, the proportion added over the period was significantly higher than the proportion removed $(P>0.0126)$. The confidence interval in this case was one of the larger ranges. For the garden center channel, the relationship was not significant $(P$ $>0.317)$.

ArRANGe AND/OR PAY FOR tRANSPORTATION TO CUSTOMER. For neither channel was there sufficient evidence to indicate that the added proportion was different from the removed proportion.

Provide returnable shipping EQUIPMENT. For the MM channel, this item was added more frequently than it was removed over the time period $(P>$ $0.025)$. For garden centers, there was insufficient evidence to suggest that the proportions differed over the period.

ENSURE ON-TIME DELIVERY. There was no evidence to suggest that this item was added more frequently than it was removed over the time period for either channel $(P>0.317$ and $P>$ 0.179 , respectively).

TAKe BACK UNSOLd PRoduct. For the MM channel, take back unsold merchandise was not significantly different over the period at an alpha level of 0.05 . However, if the slightly less rigorous level of 0.10 was used, the difference in proportion was significant. For the garden center channel, the sample did not provide evidence to reject the hypothesis of no difference in these proportions.

SUPPLY MINIMUM VOLUME. There was no difference in proportions over the period for the MM channel. For the garden center customers on the other hand, the proportion of growers who reported that the item was removed was lower and significantly different from the proportion that added the item $(P>$ $0.046)$. The confidence interval in this case was somewhat narrower compared to most of the other intervals, indicating a more precise estimate.

REQUIRE CONTINUOUS INVENTORY REPLENISHMENT. For continuous inventory replenishment in the MM channel, the difference in proportions added and removed over the time period did not fall in the critical region at the 0.05 level $(P>0.096)$. Using the 0.10 level, however, allows us to state that the proportions did differ. For the garden center channel, on the other hand, the null hypothesis was rejected $(P>0.046)$, so continuous inventory replenishment as a requirement in the typical sales agreement was more frequently added than removed over the period.

\section{Discussion}

NUMBER OF SIGNIFICANT DIFFERENCES. Using a significance level of 0.10, five of the proportions tested were significantly higher for the MM channel compared to four for the garden center channel. This level of significance is an appropriate one in studies where there has been little prior empirical testing of relationships.

ITEMS WITH SIMILAR RESULTS BETWEEN ChANNELS. Two of the items evaluated -apply barcode stickers and use continuous inventory replacement - were significant for both channels. For apply barcode stickers, there were 10 added responses compared to one removed for the MM channel as reported in Table 1 . This was among the highest of the added responses. We expected that applying barcode stickers to products sold to MMs was common practice in 1996, so the result was unexpected. As an alternative explanation, the respondents' customer base might have changed over the period. If this was the case, responses could differ because the growers probably were selling to more MM customers, or were selling a higher proportion of output to MM customers. In those cases, the MM expectation would not be different, but the grower's response would change because output was distributed differently among the customer base. In the garden center analysis for the requirement to apply barcode stickers, there were five added cases and zero removed. The number added was in the middle of the garden center group.
It was expected that garden centers would be adding this item to the terms of sale as these firms adopted scanning capability.

The significantly higher number of added cases for continuous inventory replacement was expected in the MM channel. However, that four respondents in the garden center channel reported the addition of this sophisticated, high-technology business practice was not expected. This suggests the need for additional research into the rate at which garden centers are adopting this technology.

ITEMS THAT DIfFERED BETWEEN CHANNELS. For MMs, provide custom containers, provide returnable shipping equipment and take back unsold merchandise were the other three significantly different items. These are issues that enhance the MM's competitive position. The custom container is a product and firm differentiation tool, and was the item most frequently added to the sales agreement. Returnable shipping equipment usually is the property of the grower, and its use reduces MMs' handling requirement at the unloading point and when positioning product within the store. Taking back unsold merchandise assists the retailer by removing the risk of over-ordering, or when damage to the product results from inattentive or untrained employees. Take-backs usually take the form of account adjustments rather than physically sending the product back to the grower. The impact of this practice on growers merits further study.

For garden centers, the other two items with significantly different proportions were attach product information tags and provide minimum volume. For MMs, the information tag probably item already was a condition in 1996, and now is ubiquitous in this channel.

Evidence suggests that garden center customers also value information tags on products. Garden centers have responded by asking growers to supply that service. There were nine cases where this item was added, so it appears to have been an important garden center concern during the period.

Asking growers to agree to supply some minimum volume was another of the significant differences, suggesting a desire among some garden centers to use fewer suppliers. Each of the 
remaining suppliers would then have a larger share of the business. This supports the discussion above where the continuous inventory replenishment item was more frequently added, and may be another indication that garden centers' expectations of suppliers were changing.

For MMs, there appeared to be little interest in the on-time delivery and the minimum volume items, but these probably are superceded by the inventory replenishment systems they employ. For garden centers, custom containers, returnable shipping equipment, and take back unsold product were items where little activity appeared. Given the importance of these items to the MM segment of the industry, it would be a reasonable forecast that interest in these items would increase among garden centers.

This research is important because it addresses business practices that can increase the grower's costs and risk level. There has been little prior empirical study of these changes. The discussion of items included in the conditions of sale is based on results from a grower survey. The statistical results were limited by low response rate and the resulting small sample size. Particularly in small samples, results are sensitive to changes in a few observations. Given these statistical considerations and the limited amount of information about the terms of exchange, this research should be considered exploratory. In addition, we expected that retailers would demand more services from growers, but another factor that affected survey responses was the grower's customer base. If an increasing portion of growers' output went to MMs over the period, they would be more likely to respond that any given item was added. Results, though, generally were consistent with expectations based on industrial organization theory and experiences from other agricultural and nonagricultural industries.

\section{Literature cited}

Agresti, A. 1996. An introduction to categorical data analysis. Wiley, New York.

Carman, H., R. Cook, and R. Sexton. 1997. Marketing California's agricultural production, p. 125-150. In: J. Siebert (ed.). California agriculture: Issues and challenges. Univ. Calif. Giannini Found. Agr. Econ., Davis.

Cook, R. 2001. The U.S. fresh produce industry: An industry in transition, p. 5-30. In: A. Kader (ed.). Postharvest technology of horticultural crops, Pub. 3311, University of California Division of Agriculture and Natural Resources, Davis.

Dillman, D. 1999. Mail and internet surveys: The tailored design method. 2 nd ed., Wiley, New York.

National Gardening Assn. 2002. National gardening survey 2001, Burlington, Vt.

Navajas, R. 2003. Analyzing changes in contractual practices in the Louisiana nursery industry. Louisiana State University Electronic Thesis and Dissertation Collection. 2 Sept. 2003. <http://etd.lsu.edu: 8085 /docs/available/etd-0410103$101627 />$.

Perosio, D., E. McLaughlin, S. Cuellar, and K. Park. 2001. FreshTrack 2001: Supply chain management in the produce industry. Cornell University, Ithaca, N.Y.

The Economist. 2001. Wal-Mart around the world. Econ. Nwspr., New York.

Tucker, I. and R. Wilder. 1977. Trends in vertical integration in the U.S. manufacturing sector. J. Ind. Econ. 25:81-94. 